\title{
How should medical researchers respond to false copyright infringement claims?
}

\author{
Sung Pil Park', Eric Yong Joong Lee ${ }^{2,3}$ \\ ${ }^{1}$ Korea Advanced Institute of Science and Technology, Daejeon; ${ }^{2}$ College of Law, Dongguk University, Seoul; ${ }^{3} Y$ IJUN Institute
} of International Law, Seoul, Korea

\section{Abstract}

Serious concerns have been raised about the Morisky Medication Adherence Scales (MMAS4 and MMAS-8) ever since researchers from Asia and other regions were claimed to have used the MMAS without a license. Donald Morisky and his team have claimed that numerous authors have infringed copyright, trademark, or other rights over the MMAS. This case study will scrutinize whether the MMAS is protected by any intellectual property rights, including copyright and trademark. In many cases, the authors have not applied the MMAS for their research, but have only introduced or described the MMAS in papers that are accessible and open to the public. The MMAS is a measure to keep track of and check the regularity and accuracy with which patients take their medications; it is not meant as a diagnosis and does not form a basis for treatment plans. If another researcher rephrases the questions in a way that achieves a certain level of originality, not infringing the original expressions of the MMAS, then Morisky and his team may not be able to claim infringement of its copyright. Even assuming that the MMAS is subject to copyright, the authors can raise a "fair use" defense. Concerted actions may be necessary for researchers to protect academic integrity and the public nature of scholarly works. The fair use of the MMAS in a scholarly article should not be barred by false copyright infringement claims.

Keywords

Survey questionnaires; Copyright; Fair use; Infringement; License

Received: July 16, 2019

Accepted: July 26, 2019

Correspondence to Eric Yong Joong Lee grotian@dongguk.edu

ORCID

Sung Pil Park

https://orcid.org/0000-0002-7778-4814

Eric Yong Joong Lee

https://orcid.org/0000-0001-5640-490X

\section{Introduction}

The so-called Morisky Medication Adherence Scales (MMAS-4 and MMAS-8) have become a point of contention recently [1]. Dr. Donald Morisky and his team, including Mr. Steve Trubow, claim that researchers who use the MMAS without permission "steal Dr. Morisky intellectual property" and "divulge his trademark protected trade secret scoring and coding criteria." Mr. Trubow also claims that such researchers disclose incorrect MMAS scoring and coding and thereby cause "harm to the patients." Having found multiple very similar cases where 


\section{science editing /}

medical researchers in Asia have been exposed to such infringement claims for using MMAS scoring and coding without permission, we are motivated to address the fundamental legal issue of whether Dr. Morisky's MMAS is protected under any intellectual property law, especially and most importantly copyright law.

\section{Case Analysis}

Substantive claim of copyright infringement

The first scenario to consider is when a medical researcher uses these scales (MMAS-4 or MMAS-8) as part of his/her academic research. Dr. Morisky and his company, MMAS Research LLC (MRL), are both already referred to within the medical research community. A lawsuit was recently filed by MRL against the Regents of the University of California, San Francisco (case 2:18-cv-09767; November 20, 2018). However, this case was closed on May 30, 2019 with a "Stipulation of Dismissal with Prejudice," which implies that the case was dismissed permanently based on an agreement between the parties and cannot be brought back to the court. Because the court did not render its opinion on the plaintiff's claims, we do not yet have an authoritative interpretation of the legal issues related to MMAS-related cases [2].

The general practice in the community is for researchers to send emails to Dr. Morisky and/or Mr. Trubow for permission to use the MMAS before starting their research. However, in a number of cases Morisky and Trubow did not respond to email requests until the researcher gave up on using the scale or decided to use it anyway. From the replies to the Retraction Watch article presented above, we can see quite a few instances of such "delayed responses" to license requests from researchers. We have also heard similar experiences of delayed communication with the MMAS personnel from medical researchers in Asia [1]. In cases where the researchers decided to use the MMAS anyway, Mr. Trubow sent them accusatory emails and communications for not consulting with him before the research began, and asked them to obtain "retroactive" licenses to correct their alleged infringement of copyright, trademark, or trade secrets over the MMAS, which cost significantly more than ordinary licenses [1].

Although our discussion in this article is focused on MRL's primary claim of copyright infringement, we do not consider that claims of trademark infringement or trade secret misappropriation could be established against researchers using the MMAS. First of all, researchers' use of the names of Dr. Morisky and/or the MMAS in their articles constitutes the socalled "nominative use" doctrine, which was first conceptualized in New Kids on the Block v. News America Pub case [3]. Applying this doctrine to the MMAS-related cases, we may conclude that there has been no trademark infringement by researchers, for three reasons: first, it is almost impossible to identify the MMAS and/or Dr. Morisky without mentioning their names; second, researchers usually use their names only to the extent that is necessary for such identification; and third, researchers do not imply any sponsorship or endorsement by the trademark holders. In the motion to dismiss the complaint in MRL v U.C. Regents, the defendant argued against MRL's trademark infringement claim using similar reasoning [2].

Regarding MRL's claim of trade secret misappropriation, it is not clear whether: there is any secret information possessed by MRL or Dr. Morisky, and disclosed or divulged by researchers; whether such information has any commercial value (not according to claims made by MRL or Dr. Morisky, but based on objective criteria); and whether MRL and Dr. Morisky made reasonable efforts to maintain the secrecy of the information [4]. Unless the MRL team can prove that these three conditions are met, trade secret misappropriation is not a valid claim against researchers using the MMAS, which is published and accessible online to any person. While the conditions may vary by jurisdiction, these three conditions provided in Art. Thirtynine of the Agreement on Trade-Related Aspects of Intellectual Property Rights are standard requirements for trade secret protection.

\section{Copyright infringement claims}

MRL sends a warning letter to individual researchers or to their institution (accusing the institution of being vicariously liable for the researcher's use of MMAS without a license) indicating their intent to claim copyright and other intellectual property rights [2]. In its warning letter, MRL recommends that the author(s) should throw in the towel (i.e., MRL demand full and instant compliance of the author(s) with the rules that MRL established itself). The communication between MRL (especially Mr. Trubow) and the author(s) is not reciprocal at all. MRL offers a retroactive license to the author(s) and/or their institution on a take-it-or-litigate basis. MRL usually puts the author(s) at risk by threatening to initiate a lawsuit, copying names of their lawyers [5].

Successful claims: reasons

MRL could employ some legal tactics to transform its "license" agreements into "service" agreements. Based on such agreements, MRL provides training and related services for the researchers to correctly use the MMAS. Therefore, such education and training services, as well as the "license" to use the MMAS copyright and other intellectual property rights, are furnished in consideration of the royalties paid by researchers. Therefore, it is not easy for scholars to later argue that the agreements with MRL are invalid, because they did 
already receive such "services" from MRL.

\section{Legal Analysis}

\section{Question 1: Is Morisky's scale protected under copyright} law?

Copyright protects an original expression of authorship. Therefore, this question can be reformulated as follows: Does the MMAS contain any elements of original expression in it that can be protected under the copyright regime?

Dr. Morisky's MMAS is a scale, or a system, developed to measure patients' medication adherence. This scale is based on eight simple questions on whether the patient sometimes forgets to take medication, as shown in "Table 2: The 8-Item Medication Adherence Scale" [6]. Patients are required to answer each question with a "yes" or "no." Dr. Morisky argues in his 2008 article that he "phrased" the questions to avoid certain biases in patients' answers [6]. The MMAS therefore contains some expression elements in terms of its phrasing of the questions, which may be eligible for copyright protection. However, the MMAS, as a system to assess patients' medication adherence, may be protected better as a process (or business method) patent rather than as a copyright. Patent protection is subject to whether an invention meets substantive and procedural requirements under the patent laws of each jurisdiction.

Although the MMAS may have some expression value in terms of its phrasing of the questions, such protection is likely to be very thin. In other words, if another researcher rephrases the questions from his/her own perspective, and if such rephrased questions achieve a certain level of originality that does not infringe upon the "original expression" of the MMAS, then MRL may not be able to claim infringement of its copyright.

As mentioned above, Dr. Morisky stated in his article that he phrased the questions carefully to avoid the "yes-saying" bias [6]. If certain portions of the phrases in the questions are indispensable, then the so-called "merger doctrine" could apply. Under the merger doctrine, when an idea is effectively expressed in one or only a few ways, such expression(s) cannot be protected under the copyright law, because the idea and expression(s) are merged in this situation [7]. If other researchers have no choice but to use such essential phrases (i.e., expressions), copyright law would not protect such a merged term with an exclusive right. This is the crux of the idea-expression dichotomy under copyright law, which is instructive in the assessment of copyright cases.

When an article contains the MMAS as a whole (i.e., borrows the exact phrases or uses phrases that are substantially similar to the original), it may at least theoretically result in copyright infringement. As this is a thin protection, however, one may avoid infringement claims by devising original expressions about the idea of measuring medication adherence.

Question 2: Does academic use of such a scale really matter?

Even assuming that the MMAS is subject to copyright, meaning that authors using the MMAS cannot deny infringement itself, the authors can raise a "fair use" defense.

Fair use refers to any copying of copyrighted material done for a transformative purpose (i.e., creating new value) [7]. Criticisms, news reports, comments, book reviews, or parodies are typical examples of fair use. The quotation of short phrases and models, with valid citations, in scholarly articles is, of course, another valid form of fair use. However, whether the use of copyrighted material is actually fair use needs to be assessed carefully and on a case-by-case basis. For instance, copyright laws in the U.S. provide a guideline (four-factor test) in deciding the applicability of the fair use defense as follows [8]: the purpose and character of the use; the nature of the copyrighted work; the amount and substantiality of the portion taken; and the effect of the use upon the potential market.

In MRL $v$ U.C. Regents, the Regents' Counsel suggested that the fair use defense could be reasonably applied to this case under the United States Copyright Act. In its motions to dismiss the complaints, the defendant argued that the reproduction of the MMAS at issue was for research purposes only; that "simple factual questions" are less protected; that reproduction of only a part of the MMAS for scholarly purposes is fair use; and that the plaintiff's argument of lost license (or lost revenue) is circular reasoning, because the defendant's reproduction of the MMAS for research is protected as fair use [2].

\section{Points to Be Considered}

\section{What if your team has not started its planned research?}

Do not use MMAS at all. Try to find alternative measures. If the MMAS has any value as a system, attempt to rephrase the questions and restructure the system based on your own scholarly views. Journal editors and publishers may make it a rule not to use the MMAS at all and suggest alternative measures to avoid any friction with false intellectual property claims.

What if your team has already published an article containing the MMAS without permission, and you received a warning letter from MRL?

If one does not have the time to deal with the issue, but has the requisite financial resources, then s/he may settle the dispute with a payment. However, it should be remembered that this is precisely the environment in which false claims are be- 
science editing /

coming more common. Of course, if the article clearly copied the MMAS as a whole (including its expression elements, which trigger thin protection), then the odds may be in favor of MRL. However, even if MMAS is reproduced as a whole, it is not the end of the game. Hopefully, an interpretation of copyright law regarding the MMAS will be provided by the courts. Nonetheless, the precedents are ample even now on fundamental copyright law issues such as which elements are required for copyright protection; when an idea and expression are merged; and how the fair use defense can set alleged infringers free from infringement claims.

What if you are a journal editor and the authors of an article in your journal received a warning letter from MRL?

Journal editors and publishers, who have a genuine interest in policing devastating practices such as those promulgated with regard to the MMAS, may step up to ally with victimized authors and call false claimants to court seeking a declaratory judgment that there is no valid infringement claim of any intellectual property. Concerted action may be necessary to protect academic integrity and the public nature of scholarly works. False claimants have prospered in the present environment, partially thanks to the inaction of scholars or due to situations where scholars are under time pressure to meet deadlines for graduation or promotion.

What if your team has already published an article mentioning the MMAS without use of the scale, and you received a warning letter from MRL?

MRL is believed to look for use of the MMAS regularly in medical literature databases. Upon finding this term in any journal, they probably commence by dispatching a threatening email to authors of that article accusing them of infringement of copyright law. However, just mentioning Dr. Morisky and/or the MMAS in the text does not by itself amount to copyright infringement. In this case, the authors and editors do not need to react to the threatening email; instead, they should ignore it. There will be no continuing contact from MRL. Another method to avoid interacting with them is to treat their threatening emails as spam. It is of course recommended that researchers and editors not mention this scale in the medical literature in any way. Without this scale, patients with hypertension - or any similar condition - can maintain their medication regimen without difficulty through physicians', pharmacists' or family members' assistance.

\section{Conclusion}

This research provides evidence that medical researchers who used Dr. Morisky's MMAS for their research did not in fact infringe any intellectual property rights, including the copyrights of MRL or Dr. Morisky. A simple comment on Dr. Morisky's work and a brief introduction of the MMAS does not constitute intellectual property infringement, either. In fact, the MMAS was made open to the public through Dr. Morisky's article via PMC [7]. Fair use of the MMAS in a scholarly article should not be barred by false copyright infringement claims. In many cases, Dr. Morisky and his team have claimed that authors applied the MMAS incorrectly and that their primary motivation for claiming intellectual property infringement is to correct such errors [1]. However, use of the MMAS has nothing to do with the treatment of patients, because MMAS is a measure to check how regularly and accurately patients take medication, rather than a tool for diagnosis or treatment.

Just introducing or describing the MMAS without a license in a research paper is not an infringement of any copyright. In conclusion, the authors would like to address the following three points that researchers should keep in mind. First, the MMAS is a system to measure medication adherence, rather than an original expression of authorship protected under copyright law. Second, even if there is room for copyright protection with regard to the phrasing of MMAS questions, such protection is thin, and the merger doctrine and fair use defense under copyright law may effectively defeat infringement claims. Third, researchers may be well-advised to behave with extreme caution to avoid using the MMAS and to seek out alternatives that are free from false claims, and journal publishers likewise may well advise their authors not to use the MMAS.

\section{Conflict of Interest}

No potential conflict of interest relevant to this article was reported.

\section{Acknowledgments}

This work was supported by the research program of DELTA Research Center at KAIST and the research program at Dongguk University-Seoul.

\section{Disclaimer}

All information contained in this article is for general informational and scholarly purposes only and does not constitute legal advice or representation. No reader of this article should act or refrain from acting on the basis of information in this article without first seeking legal advice from their attorney in the relevant jurisdiction. Only the individual attorney of the 
readers can provide assurances that the information contained herein and their interpretation of it are applicable or appropriate to their particular situation. The views expressed in this article are those of the authors only and do not necessarily reflect the opinion of this journal or any third party institution. All liability with respect to actions taken or not taken based on the contents of this article are hereby expressly disclaimed.

\section{References}

1. Stern V. If you use this research tool without permission, you'll hear about it [Internet]. [place unknown]: Retraction Watch; 2017 [cited 2019 Jul 21]. Available from: https://retractionwatch.com/2017/01/26/use-researchtool-without-permission-youll-hear/

2. MMAS Research, LLC et al v. The Regents of The University of California et al: case number 2:18-cv-09767 [Internet]. [place unknown]: JUSTIA; 2018 [cited 2109 Jul 22]. Available from: https://dockets.justia.com/docket/california/cacdce/2:2018cv09767/729345

3. New Kids on the Block v. News America Pub., Inc., 745 F.
Supp. 1540 (C.D. Cal. 1990).

4. TRIPS Agreement Section 7: Protection of Undisclosed Information. Article 39 [Internet]. Geneva: World Trade Organization [cited 2019 Jul 22]. Available from: https:// www.wto.org/english/docs_e/legal_e/27-trips_04d_e.htm

5. Marcus A. Pay up or retract? Survey creator's demands for money rile some health researchers [Internet]. Washington, DC: ScienceMag.org; 2017 [cited 2019 Jul 22]. Available from: https://www.sciencemag.org/news/2017/09/ pay-or-retract-survey-creators-demands-money-rilesome-health-researchers

6. Morisky DE, Ang A, Krousel-Wood M, Ward HJ. Predictive validity of a medication adherence measure in an outpatient setting. J Clin Hypertens (Greenwich) 2008;10:34854. https://doi.org/10.1111/j.1751-7176.2008.07572.x

7. Goldstein P, Reese RA. Copyright, patent, trademark and related state doctrines: cases and materials on the Law of Intellectual Property. 6th ed. St. Paul: Foundation Press; 2008.

8. US Copyright Law 17 U.S. Code. Section 107. Limitations on Exclusive Rights: Fair Use. 